\title{
The Effect of Preschooler's Shyness on School Readiness: Mediating Effect of Everyday Executive Function
}

\author{
Yu Ri Ryu ${ }^{1}$, Min Ju Kang ${ }^{2}$ \\ Master of Education, Early Childhood Education Major, Graduate School of Education, Yonsei University, Seoul, Korea ${ }^{1}$ \\ Associate Professor, Department of Child \& Family Studies, Yonsei University, Seoul, Korea ${ }^{2}$ \\ 유아의 수줍음이 학교준비도에 미치는 영향에서 일상의 실행기능의 매개효과 \\ 류유리 ${ }^{1}$, 강민주 ${ }^{2}$ \\ 연세대학교 교육대학원 유아교육전공 석산, 연세대학교 아동·가족학과 부교수 2
}

Objectives: The purpose of this study was to examine the mediating effect of everyday executive function in the relationship between preschooler's shyness and school readiness.

Methods: Participants consisted of 236 five-year-old preschoolers. For data analyses, descriptive statistics, t-tests and Pearson's correlation and structural equation modeling were used. Bootstrapping method was applied to examine the significance of the mediating effects.

Results: First, preschool girls were reported to show higher school readiness than preschool boys. Moreover, the children with sibling(s) were reported to have higher school readiness than those with no sibling(s). Employment of mothers and weekly private education hours had no significant effect on school readiness. Second, the everyday executive function mediated the relationship between the preschooler's shyness and school readiness.

Conclusion: This study has implication for investigating gender and sibling difference in shyness and the mediating mechanism of explaining variance in the school readiness of preschoolers. The limitations and more implications of this study are also discussed.

Keywords: school readiness, shyness, everyday executive function

\section{Introduction}

인간은 발달과정에서 다양한 생태적 전이를 경험하고 적응해 간다. 그 중 아동의 초등학교 입학은 그 이전의 영유아기 가정 및 교육·보육기관의 경험과 질적으로 다른 차원의 새로운 경 험이다. 즉, 유아는 초등학교 입학을 통해 학교라는 울타리 안 에서 공동체 생활을 시작하게 되며, 부모나 교사의 도움보다 는 스스로 학교 환경에 적응하면서 주어진 과제나 활동을 수 행해야 한다. 따라서 보다 성공적인 학교생활을 위해서는 기

Corresponding Author: Min Ju Kang, Associate Professor, Department of Child \& Family Studies, Yonsei University, 50 Yonsei-ro, Seodaemun-gu, Seoul, Korea

E-mail:mjkang@yonsei.ac.kr
본적인 생활습관에서부터 표현능력, 인지 능력에 이르기까지 적절한 준비가 필요하다.

학교라는 새로운 환경에 잘 적응할 수 있는 총체적인 발달 역량은 학교준비도(school readiness)라는 개념으로 설명할 수 있다. 과거에는 이러한 학교준비도를 읽기, 쓰기, 셈하기 등 인 지적 차원의 준비에 초점을 두었다. 그러나 최근에는 초등학 교 학습에 필요한 기초적인 기술로 인지적인 능력뿐만 아니라 사회·정서 발달, 의사소통능력, 일반적 지식 등을 포괄하는 개 념으로 보고 있다(Murphey \& Burns, 2002). 다시 말해 아동과

(C)The Korean Association of Child Studies

This is an Open Access article distributed under the terms of the Creative Commons Attribution Non-Commercial License (http:// creativecommons.org/licenses/by-nc/4.0) which permits unrestricted noncommercial use, distribution, and reproduction in any medium, provided the original work is properly cited. 
아동을 둘러싼 환경적 경험들 간의 상호작용에 결과로 간주하 여 학업수행 뿐 아니라 학교생활 전반에 걸친 사회적 적응 영 역을 포괄하는 개념으로 보고 있다(Shim \& Woo, 2019).

선행연구에 따르면 학교준비도는 유아가 초등학교에 입학 한 후 1 학년에서의 읽기 및 수학 성적을 예언하는 중요한 변인 인 것으로 밝혀졌다(Schaefer \& McDermott, 1999). 또한 일반적 으로 유아교육기관에서 초등학교로의 전이 시 학교준비도 수 준이 낮을수록 정서적 위축이나 우울 등의 내면화 문제를 경 험할 가능성이 높고, 과제 수행이 어려워 지속적인 학업문제 를 나타낼 수 있다고 보았다(Y.-J. Park \& Chung, 2008). 이렇듯 학교준비도 수준에 따라 초등학교에서의 학교생활을 예측할 수 있으므로 미국 등 여러 나라에서는 학교준비도가 낮은 유 아들을 조기 중재를 하여 수준이 향상될 수 있도록 돕고 있다 (Jordan, Kaplan, Nabors, \& Locuniak, 2006). 또한 이러한 학교준 비도 수준에 있어서의 개인차를 나타내는 요인에는 무엇이 있 는지 살펴보는 것은 유아가 학교생활을 잘 할 수 있도록 돕는 지원방안을 모색함에 있어 중요한 기초 자료가 될 것이다.

취학 전 유아의 학교준비도에 영향을 미치는 변인에 대한 연구는 국내·외에서 지속적으로 진행되어 왔다. 그 중에서도 기질적 측면인 수줍음이 학교준비도에 어떠한 영향을 미치는 가에 대해서는 연구 모델이나 연구대상에 따라 결과가 조금씩 다르게 나와 지금까지도 매우 흥미로운 요인으로 남아 있다. Zhang, Eggum-Wilkens, Eisenberg와 Spinrad (2017)에 의하면 수 줍음이 만 6-7세 유아들의 학업성취도에 직접적인 영향력은 없 었으나 수줍은 유아들은 또래에 의한 수용도가 낮았으며, 이를 매개로 추후 학업성취도에 부정적 영향을 미치는 것으로 나타 났다. 만 3-5세 유아기는 또래와 본격적으로 사회적 관계를 형 성하는 시기이다. 유아기 자녀를 둔 부모는 자녀가 매사에 사 교적이고 적극적인 태도로 행동하기를 바란다. 그러나 수줍음 (shyness)은 사교적인 행동과는 대조되는 개념으로, 낮선 사람 이나 새로운 상황에서 편안하게 행동하지 못하는 특성을 말 한다. 때문에 수줍은 유아는 낮설음으로 인한 어려움을 경험 하고, 이로 인해 타인과의 관계에서도 스트레스를 겪게 된다 (Coplan, Prakash, O’Neil, \& Armer, 2004). 이러한 수줍음 성향 은 초등학교로의 전이 과정에서도 인지적 능력이나 학습에 대 한 태도 뿐 아니라 자신의 생각을 표현하는 능력과 사회·정서 발달 등에 있어 부정적인 영향력을 미친다고 밝혀져 왔다.

우리나라의 연구에서도 Y. H. Kwon (2014)의 연구에서 유 아의 수줍음은 사회적 유능성과 부적 상관관계가 있는 것으 로 나타나, 수줍음이 사회적 상호작용이나 또래 협동, 정서 표 현 등에 영향을 미칠 것이라고 예측해 볼 수 있다. 또한 Yi와
Kwon (2008)의 연구에서는 기질적으로 수줍은 유아와 일반 유아의 이야기 구성 능력 차이를 살펴본 결과, 수줍은 유아가 책을 읽고 이야기를 구성하는 능력이 낮게 나타나 수줍음 성 향이 인지 및 문해 능력에도 부정적인 영향을 미치고 있음을 알 수 있다. 이처럼 수줍음이 학교준비도와 관련된 발달의 여 러 영역에 부정적인 영향을 주는 변인 중 하나로 꼽히기 때문 에 미국에서는 일찍이 수줍음의 조기 중재를 위한 프로그램을 개발하고 보급해왔으며(Zimbardo, 1977), 우리나라에서도 수 줍음 극복 프로그램을 개발하여 그 효과를 검증하기도 하였다 (Y.-N. Park \& Doh, 2006).

앞서 살펴본 바와 같이 일반적으로 수줍은 유아는 사교성 이 낮고 위축되는 경향이 있기 때문에 학교생활을 함에 있어 사회·정서 및 인지발달, 의사소통 등의 영역에서 어려움을 경 험할 것이라고 예상해 볼 수 있다. 그러나 수줍음과 학교준비 도 간의 직접적인 연관성을 살펴본 연구는 드물며, 기존의 연 구 결과들 또한 전적으로 일관성 있는 결과를 나타내지는 않 고 있다. 이는 수줍은 유아일지라도 표현능력이나 인지능력 이 뛰어날 수 있으며, 유아의 수줍음이 학교준비도와 직접적 인 연관성이 있을 수도 있지만 수줍음과 학교준비도 간 관계 에서 수줍음에 의해 영향을 받는 변인임과 동시에 학교준비 도의 영향을 미칠 수 있는 매개변인이 존재할 수 있음을 예측 해 볼 수 있다. 일상의 실행기능(everyday executive function)은 목표를 달성하기 위해 자신의 행동과 사고를 조절하고 부적 절한 행동을 억제하며 대안을 탐색하는 인지과정이다(Gioia, Isquith, Guy, \& Kenworthy, 2000). 이러한 능력은 변화하는 환 경에서 요구하는 것에 적절하게 대처하기 위해서 사고와 행동 을 조절하고 관리하는 것을 뜻한다(Y. Kim \& Kwak, 2014). 하 지만 수줍음 성향을 가진 유아가 낮설고 긴장된 상황에서 나 타내는 억제적 행동은 일상의 실행기능을 수행함에 있어 영향 을 줄 것이라고 예측해 볼 수 있다.

실제로 수줍음과 어휘능력, 일상의 실행기능 간의 관계 대해 검증한 Blankson, O’Brien, Leerkes, Marcovitch와 Calkins (2011)의 연구에 따르면 수줍음은 시험 등 일상생활에서 경험 할 수 있는 긴장상황에서 인지적 실행기능이 제 기능을 발휘 하는 것에 부정적인 영향을 준다고 밝혀졌다. 또한 다수의 선 행연구에서도 수줍은 성향을 가지고 있는 유아는 새로운 또래 나 성인과 접촉하는 상황에서 수줍음 수준이 증가하게 되면, 당면한 과제에 집중하는 능력이 저하될 수 있고 결과적으로 는 실행기능이 방해를 받을 수 있는 것으로 밝혀져(Arnold \& Cheek, 1986; Ludwig \& Lazarus, 1983), 수줍음이 유아의 일상 의 실행기능에 부정적인 영향을 미치고 있음을 증명하였다. 
이러한 일상의 실행기능은 만 3-5세 유아기에 급격한 발달 을 이룬다(Nilsen, Huyder, McAuley, \& Liebermann, 2017). 또한 이 시기 유아들 간 일상에서 나타나는 실행기능의 개인적 차 이는 학교준비도와 학업능력·언어·사회적 유능성과 같은 여 러 발달 영역에 영향을 미친다고 밝혀져 왔다(Best, Miller, \& Naglieri, 2011; Valiente, Lemery-Chalfant, \& Castro, 2007).

구체적으로 만 5세의 일상의 실행기능이 초등학교 입학 후 수업참여에 미치는 영향에 대해 살펴본 Nilsen 등(2017)의 연 구에서는 일상의 실행기능 수준이 높은 유아일수록 초등학교 1 학년 때 학업을 방해하는 부적절한 행동이 적은 것으로 나타 났다. 또한 우리나라의 연구 중 Y. Kim과 Kwak (2014)의 단기 종단연구에서는 만 4세 유아의 실행기능이 만 6세가 되었을 때 읽기 능력과 어떤 관련이 있는지 살펴보았다. 그 결과 만 4 세 때의 실행기능 하위영역 중 작업 기억이 만 6세 때 읽기유 창성을 유의미하게 예측하였고, 만 4세 때의 억제능력과 인지 적 유연성이 만 6세 때 읽기 이해도에 유의미한 영향을 미치는 것으로 나타나 일상의 실행기능이 학교준비도에 영향을 미치 는 중요한 변인임을 예측해 볼 수 있다.

결국 유아의 수줍음이 일상의 실행기능을 예측하는 변인이 며 동시에 유아의 수줍음과 일상의 실행기능은 학교준비도를 예측하는 변인임을 알 수 있다. 따라서 유아의 수줍음이 취학 전 유아의 학교준비도를 낮추는 영향 관계에서 일상의 실행기 능은 두 변인의 관계를 정적으로 매개할 것이라고 추론해 볼 수 있다. 그러나 이를 경험적으로 증명한 연구(Blankson et al., 2011)가 부족한 실정이다. 이에 따라 본 연구에서는 취학 전 유아가 나타내는 기질적 수줍음이 학교준비도에 부적 영향을 미치는 과정에서 인지적 조절 능력인 일상의 실행기능의 매개 효과를 검증해보고자 한다.

한편 앞서 유아의 학교준비도에 영향을 미칠 수 있는 변인 으로 살펴본 수줍음과 일상의 실행기능 외에도 학교준비도의 개인적 차이를 나타낼 수 있는 요인은 다양하다. 국내 연구에 서는 성별(Bhang \& Chung, 2015), 연령(Cho, 2002), 자기조절 력(S. H. Lee \& Hwang, 2014), 가정환경(Jun \& Choi, 2015), 부 모양육태도(Y. Kim, Koo, \& Kim, 2019), 유아교육기관과 교사 (W. Lee, 2017; Min, 2019; Song, 2019), 사교육 참여(Guk, 2016) 등과 관련된 연구결과가 보고된 바 있다. 그러나 형제유무, 어 머니의 취업여부, 사교육 참여 시간에 대해서는 학교준비도 를 구성하는 하위요인들과 유사한 정서교류능력, 의사소통 능력(N. J. Park \& Cho, 2001)이나 학습활동능력(Y.-J. Park \& Chung, 2010) 또는 학교생활과 학업 적응(Oh \& Moon, 2013) 등 부분적으로 살펴본 연구는 있지만, 이러한 개념들을 포괄
하는 학교준비도 변인과 관련지어 분석한 연구는 상대적으로 부족한 편이다. 따라서 본 연구에서는 학교준비도에 영향을 미칠 수 있는 요인으로 앞서 언급한 기질적 측면인 수줍음과 인지적 측면인 일상의 실행기능 외에 성별, 형제유무, 어머니 의 취업여부, 주당 사교육 참여 시간 변인도 함께 포함하여 살 펴보고자 한다.

그 중 유아의 성별은 가장 먼저 고려되어야 할 변인이다. Y.J. Park과 Chung (2010)의 연구에서 학령 전 아동의 성별에 따 른 차이검증 결과 하위요인인 단체생활태도, 정서교류능력, 일상생활지식, 학습활동능력 전체에서 여아가 남아보다 높게 나타났으며 그 외 다수의 연구에서 학교준비도에 대한 성차를 지지하는 결과들을 제시하고 있다. 그러나 반대로 유의한 차 이가 없다고 보고된 연구들도 있어(Choi \& Park, 2010; Yoon, Lee, \& Lee, 2017) 일관된 결과를 보이지 않고 있다. 따라서 본 연구대상 유아들 또한 성별에 따른 차이가 있는지 살펴보고 성공적인 학교 전이를 위해서 성별에 따라 어떤 도움이 필요 할지 알아 볼 필요가 있다.

다음으로 형제관계는 인간관계의 원형을 연습하고 시험해 볼 수 있는 경험의 장이다(Y. Y. Park \& Jeon, 2009). N. J. Park과 Cho (2001)는 형제유무에 따른 어휘력과 문장이해력, 표현 언 어 수준의 차이를 살펴본 결과 외동아 보다는 형제아의 언어 능력이 높았으며, 특히 동생이 있는 형, 언니의 경우 표현 언 어 수준이 높다는 흥미로운 연구결과를 제시하기도 하였다. J. W. Kim과 Shon (2009)의 연구에서는 형제유무가 대근육 발달 에 영향을 미친다고 밝혀, 형제유무가 여러 발달 영역을 포괄 하고 있는 학교준비도에도 영향을 미치는지 살펴볼 필요가 있 다. 또한 최근에는 형제 수가 감소하는 추세이기에 형제유무 의 의미와 발달적 기여에 대한 고찰이 더욱 필요하다.

맞벌이 가정이 늘어나고 있는 사회적 추세를 감안한다면 자녀의 발달에 영향을 미칠 수 있는 요인으로 어머니의 취업 여부를 고려해 볼 수 있을 것이다. 실제로 어머니의 취업여부 는 자녀양육에 대한 태도, 모-자녀 상호작용에 영향을 미칠 수 있기 때문이다(J. H. Jeong \& Kang, 2019; S. Y. Jung, 2014). 국 내 선행연구 중 Oh와 Moon (2013)의 연구에 따르면 미취업모 의 자녀는 취업모의 자녀보다 학교생활과 학업 적응을 더 잘 하는 것으로 나타났다. 그러나 J. Chung (2019)의 연구에서는 취업모의 자녀일지라도 부모가 아동의 학교생활에 대한 관심 을 가지고 적극적으로 개입하면 학교 적응 수준에 정적인 영 향을 준다고 보았다. 따라서 어머니의 취업여부에 따른 취학 전 유아의 학교준비도의 차이가 있는지 살펴보고, 차이가 있 다면 어떠한 선제적 접근이 필요할지 살펴볼 필요가 있다. 
마지막으로 유아의 주당 사교육 참여 시간은 학교준비도 와 관련하여 관심을 가지고 연구되어 온 변인 중 하나이다. 많 은 선행연구에서 사교육 참여 여부에 따른 학교준비도 수준 에 차이가 없다고 밝혀졌다(Guk, 2016; J.-H. Kim, Kim, \& Yu, 2011). 그러나 유아의 조기 사교육 시간이 점차 늘어나고 있는 현 시점에, 단순히 사교육 참여 여부에서 더 나아가 사교육 참 여 시간과 학교준비도 간의 관계를 다시금 재조명해 보는 것 은 의미 있는 과정일 것이다.

따라서 본 연구에서는 학교준비도와 관련이 있는 것으로 가정 되는 성별, 형제유무, 어머니 취업여부 및 주당 사교육 참 여 시간 변인들에 대해 살펴보고 수줍음이 학교준비도에 미치 는 영향에서 일상의 실행기능의 매개효과를 분석해보고자 한 다. 이를 통해 유아기 일상의 실행기능의 중요성을 재고하고 수줍은 유아의 학교준비도 증진방안에 대해 함께 모색해 보고 자 한다.

\section{연구문제 1}

유아의 성별, 형제유무, 어머니의 취업여부, 주당 사교육 참여 시간에 따른 학교준비도의 차이 및 관계가 있는가?

\section{연구문제 2}

유아의 수줍음은 일상의 실행기능을 매개로 학교준비도에 영 향을 미치는가?

\section{Methods}

\section{연구대상}

본 연구는 서울시와 경기도, 강원도, 충청남도, 대전시에 위치 하고 있는 국공립·민간·직장 어린이집 8곳과 사립 유치원 3 곳에 재원중인 만 5 세반 유아 236명을 대상으로 하였다. 또한 연구대상 유아는 현 유아교육기관에서의 재원기간이 6개월 이상인 유아로 선정하였다. 전체 유아의 연령은 평균 73.36개 월 $(S D=3.54)$ 이었으며, 유아의 주당 사교육 참여 시간은 평균 2.35 시간 $(S D=2.42)$ 이었다. 본 연구에서 만 5세반 유아를 연 구 대상으로 선정한 이유는 유아의 학교준비도를 연구한 연구 들(Bhang \& Chung, 2015; Chi, Jung, Jeung, Ahn, \& Park, 2006; S. Kwon \& Lee, 2018)에서 만 5-6세 유아를 대상으로 하고 있 고, 만 5세 무렵에 일상의 실행기능이 질적·양적으로 활발하 게 발달하며 눈에 띄는 변화가 나타난다는 선행연구(Zelazo \&
Carlson, 2012)에 근거하였다.

\section{연구도구}

본 연구의 측정변인 중 성별, 형제유무, 어머니의 취업여부, 사 교육 참여 여부 및 주당 사교육 참여 시간은 어머니용 질문지 를 통해 수집하였다. 또한 사교육 참여 여부에 대한 질문에서 사교육 참여의 기준은 2015년 Korea Institute of Child Care and Education (KICCE)이 발행한 '영유아 교육·보육비용 추정 연 구(III)'의 사교육비 지출 기준에 근거(J. W. Lee, Park, \& Park, 2015)하여, 영유아의 교육과 보육을 제공하는 공적인 성격을 가진 유치원과 어린이집에서 이루어지는 모든 교육·보육 활 동 이외에 부모가 영유아의 교육·보육을 위한 목적으로 순전 히 개인 부담으로 지출하여 참여하는 교육으로 규정하여 조사 를 실시하였다. 참여 항목의 예로는 개인·그룹 지도, 문화센 터, 학습지 등이 있다.

\section{학교준비도 척도}

Murphey와 Burns (2002)의 학교준비도(Ready Kindergartners School Readiness)척도를 한국아동패널 연구진이 번역하여 7차 조사 데이터에 사용한 문항(J. Lee et al., 2015)을 유아의 담임 교사가 평정하였다. 학교준비도 척도는 사회정서발달 6 문항, 학습에 대한 태도 8 문항, 의사소통 3 문항, 인지발달 및 일반적 지식 5 문항으로 구성된 총 22문항의 4점 Likert식 척도이다. 담 임교사는 평소 유아의 행동을 근거로 각 문항에 대하여 전혀 그렇지 않다(1점), 별로 그렇지 않다(2점), 조금 그렇다(3점), 매우 그렇다(4점) 중에 평정하도록 되어 있으며 유아가 받는 점수가 높을수록 각 하위요인의 학교준비도가 높음을 의미한 다. 예시 문항으로는 사회정서발달은 "하루일과 변화에 잘 적 응한다.”, 학습에 대한 태도는 "어떤 문제를 해결하기 위해 다 양한 전략을 사용한다.”, 의사소통능력은 “욕구, 필요한 것, 생 각들을 말로 표현한다.”, 인지발달 및 일반적 지식으로는 “책 의 내용을 이해한다.” 등이 있다. 학교준비도 척도의 전체 신 뢰도 계수는 .93이며, 하위 영역별 신뢰도 계수 Cronbach's $\alpha$ 는 사회정서발달 .78 , 학습에 대한 태도 .87 , 의사소통 .80 , 인지발 달 및 일반적 지식 .77 이다.

\section{수줍음 척도}

Rothbart (1996)의 'Children's Behavior Questionnaire (CBQ)' 
를 K.-O. Lee (2004)가 번역하고 수정하여 타당화 한 척도를 사용하였다. $\mathrm{CBQ}$ 는 외향성(surgency), 부정적 정서(negative affection), 주의 통제(effortful control) 3 개의 영역으로 구성되 어 있고, 그 아래 총 15 개의 하위 영역을 포함하고 있다. 외향 성은 접근성, 강한 자극 선호성, 미소/웃음, 활동 수준, 충동 성, 수줍음의 하위 영역을 포함하고 있으며, 본 연구에서는 외 향성의 하위영역 중 수줍음을 측정하는 13 문항을 사용하였 다. 어머니는 평소 유아의 모습을 근거로 각 문항에 대하여 전 혀 그렇지 않다(1점), 대체로 그렇지 않다(2점), 약간 그렇지 않다(3점), 반반이다(4점), 약간 그렇다(5점), 대체로 그렇다(6 점), 정말 그렇다(7점)의 7점 척도로 응답하도록 되어 있다. 또 한 점수가 높을수록 수줍어하는 기질적 성향이 높음을 의미 한다. 예시 문항으로는 "우리 아이는 낮선 사람이 자기에게 크 게 관심을 줄 때 당황해한다.”, "우리 아이는 금방 만난 어른 들과 이야기 할 때 긴장한다." 등이 있다. 문항의 신뢰도 계수 Cronbach's $\alpha$ 는 .91이다.

\section{일상의 실행기능 척도}

Nilsen 등(2017)이 만 3-5세 유아를 대상으로 개발하고 신뢰도 와 타당도를 검증한 "일상의 실행기능 척도(Ratings of Everyday Executive Functioning [REEF])'를 Cha와 Kim (2018)이 만 5세 유아에 맞게 번안-수정한 도구를 사용하였다. 이 척도는 일상 에서 쉽게 관찰할 수 있는 유아의 행동 중 일상의 실행기능 발 달을 의미하는 행동들을 구체적인 장소나 상황(가정, 동네, 마 트 등)별로 제시하고 있다. REEF는 76문항 단일요인으로 구성 되어 있으며, 최근 3 개월 사이 어머니가 관찰한 유아의 행동에 대해 거의 그렇지 않다(1점), 가끔 그렇다(2점), 자주 그렇다(3 점), 항상 그렇다(4점) 4점 척도로 응답하도록 되어 있다. 점수 가 높을수록 일상에서 나타나는 유아의 일상의 실행기능이 높 음을 의미한다. 예시 문항으로는 "실패하였을 때 처음의 방식 만을 고집하지 않고, 다른 방식으로 다시 도전한다.”, “주변이 어수선해도 하던 일에 집중한다.” 등이 있다. 문항의 신뢰도 계수 Cronbach's $\alpha$ 는 .96이었다.

\section{연구절차}

본 조사는 선행연구에서 학교준비도 평정에 적합한 시기를 입 학 6개월 전이라고 제안하고 있어(Y.-J. Park \& Chung, 2008), 어린이집과 유치원 여름방학이 마무리 된 시점인 8월 16일 8 월 30일과 11월 15일 11월 25일에 실시하였다.
연구대상을 선정하기 위해 본 연구자는 서울시와 경기도, 강원도, 충청남도, 대전시에 위치한 어린이집과 유치원을 연구 자가 임의로 선정하여 각 기관에 연구 참여 협조를 구하였다. 연구대상 표집을 다양한 지역(도시, 농어촌지역, 산간지역, 공 단지역 등)에서 실시한 이유는 학교준비도에 영향을 미칠 수 있는 사회인구학적 특성의 분포를 다양화하기 위해서였다.

학교준비도를 평정하는 담임교사는 3월부터 담임을 맡아 본 연구가 진행된 8월 11월까지 중도에 교체된 적이 없는 교 사로서 최종적으로 연구 참여에 동의한 어린이집과 유치원의 교사들로 선정하였다. 연구자가 담임교사에게 연구에 대한 전 반적인 내용을 소개하고 응답 예상 소요시간과 유의사항에 대 해 설명한 후 학교준비도 척도를 배부하였다. 수줍음과 일상 의 실행기능 척도는 연구 참여에 동의한 어머니를 대상으로 담임교사를 통해 질문지를 배부하고, 일주일 뒤 본 연구자가 직접 기관을 방문하여 질문지를 회수하는 방식으로 조사를 진 행하였다.

\section{자료분석}

연구를 위해 수집된 자료는 SPSS 25.0 (IBM Co., Armonk, NY) 프로그램과 AMOS 21.0 (IBM Co., Armonk, NY)프로그램을 사용하여 다음과 같은 방법으로 분석하였다. 첫째, 성별, 형제 유무, 어머니의 취업여부에 따른 측정변인들의 평균 차이를 알아보기 위해 독립표본 $t$ 검증을 실시하였다. 또한 주당 사교 육 참여 시간과 수줍음, 일상의 실행기능, 학교준비도 간의 상 관관계를 파악하기 위해 Pearson의 적률상관분석을 실시하였 다. 둘째, 유아의 수줍음과 일상의 실행기능이 학교준비도에 미치는 영향을 살펴보기 위해 경로분석(path analysis)을 실시 하였고, 매개효과 유의성을 검증하기 위해 부트스트래핑(bias corrected bootstrapping) 방법을 적용하였다.

\section{Results}

\section{성별, 형제유무, 어머니의 취업여부, 주당 사 교육 참여 시간에 따른 측정변인의 차이 및 상관관계 분석}

성별, 형제유무, 어머니의 취업여부에 따른 측정변인들의 차 이를 분석한 결과는 Table 1 과 같다. 구체적으로 유아의 성별 에 따른 측정변인의 차이를 살펴본 결과, 유아의 학교준비도 
Table 1

Mean Differences of the Study Variables According to the Demographic Characteristics

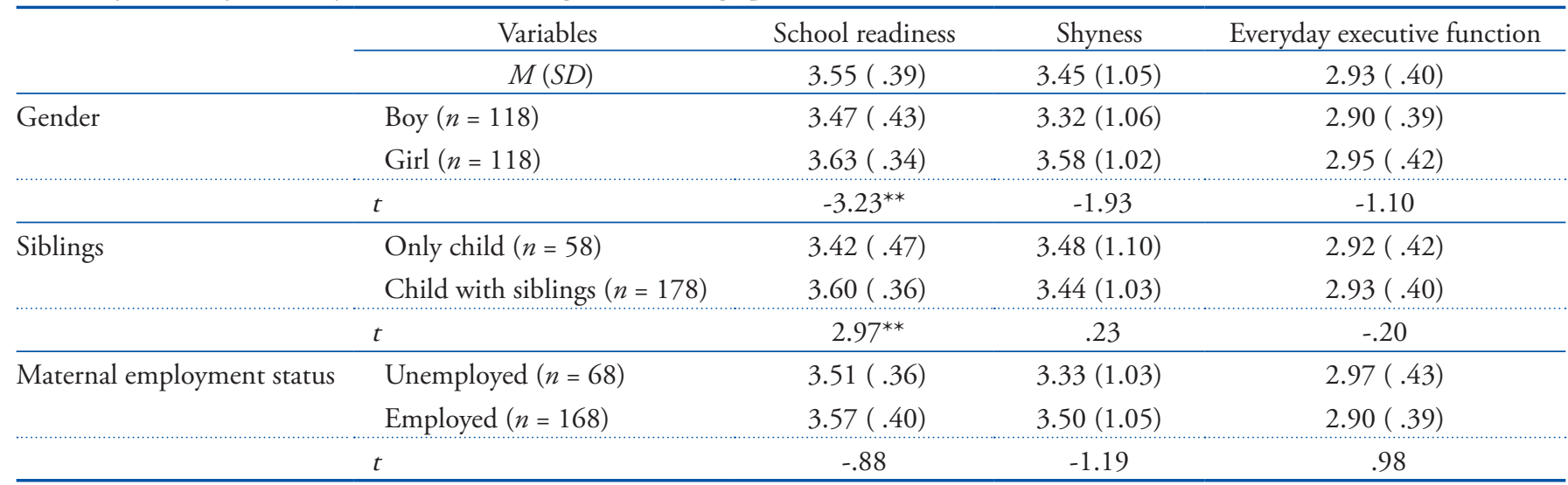

Note. $N=236$.

${ }^{* *} p<.01$.

Table 2

Correlation Coefficients Among Variables

\begin{tabular}{|c|c|c|c|c|}
\hline Variables & 1 & 2 & 3 & 4 \\
\hline 1. Private education participation hours per week & - & & & \\
\hline 2. School readiness & .01 & - & & \\
\hline 3. Shyness & -.04 & -.12 & - & \\
\hline 4. Everyday executive function & .01 & $.20^{* *}$ & $-.27^{* *}$ & - \\
\hline
\end{tabular}

Note. $N=236$.

${ }^{* *} p<.01$.

의 경우 남아 집단 $(M=3.47, S D=.43)$ 이 여아 집단 $(M=3.63$, $S D=.34)$ 보다 유의한 수준으로 더 낮게 나타났다 $(t=-3.23, p$ <.01). 또한 유아의 수줍음과 일상의 실행기능은 유아의 성별 에 따른 유의한 차이가 나타나지 않았다. 유아의 형제유무에 따른 수줍음과 일상의 실행기능, 학교준비도의 차이를 살펴본 결과, 외동아 $(M=3.42, S D=.47)$ 보다 형제가 있는 유아 $(M=$ $3.60, S D=.36)$ 의 학교준비도가 유의한 수준으로 더 높게 나타 났다 $(t=2.97, p<.01)$. 또한 어머니의 취업여부에 따라 유아의 수줍음, 일상의 실행기능, 학교준비도의 유의미한 차이는 나 타나지 않았다.

다음으로 차이 분석을 통해 살펴보지 않았던 유아의 주당 사교육 참여 시간과 수줍음, 일상의 실행기능, 학교준비도 간 의 상관관계를 확인하기 위하여 Pearson의 적률상관계수를 산 출하였으며 결과는 Table 2 와 같다. 유아의 주당 사교육 참여 시간은 연속 변인으로 투입하여 분석하였다.

그 결과 유아의 주당 사교육 참여 시간은 학교준비도와 유 의한 관계가 나타나지 않았다. 따라서 이후 분석 과정에서 유 의한 차이와 관계가 없었던 어머니의 취업여부와 주당 사교육
참여 시간을 통제변인으로 포함하지 않고 분석하였다.

\section{유아의 수줍음이 학교준비도에 미치는 영향에서 일상의 실행기능의 매개효과 검증}

본 연구에서는 앞서 살펴본 차이 검증에서 학교준비도의 유 의미한 차이를 나타냈던 성별과 형제유무를 통제한 후, 수줍 음이 학교준비도에 미치는 영향에서 일상의 실행기능의 매개 효과를 검증하였다. 먼저 연구모형의 적합도를 확인하였다. 모형 적합도는 $\chi^{2}$ 의 $p$ 값이 .05이상이며, TLI가 .90이상, $\mathrm{CFI}$ 가 .90이상, RMSEA가 . 10 이하이면 적합하다고 판단한다. 본 연구에서는 $\chi^{2}$ 은 31.02 ( $\left.p<.01\right)$ 이고, TLI는 .94, CFI는 .97, $\mathrm{RMSEA}$ 는 .07로 본 연구모형은 만족할 만한 수준인 것으로 확 인되었다.

다음으로 구조방정식 모형의 경로계수를 확인하였고 그 결 과는 Table 3, Figure 1과 같다. 구체적으로 살펴보면 먼저 유아 의 성별 $(\beta=.23, p<.001)$ 과 형제유무 $(\beta=.21, p<.001)$ 는 학교 준비도에 직접적인 영향을 미쳤다. 
Table 3

Path Estimates of Latent Variables

\begin{tabular}{lccc}
\hline \multicolumn{1}{c}{ Path of variables } & $B$ & $\beta$ & $S E$ \\
\hline Gender $\rightarrow$ School readiness & 1.11 & $.23^{* * *}$ & .32 \\
Siblings $\rightarrow$ School readiness & 1.22 & $.21^{* * *}$ & .37 \\
Shyness $\rightarrow$ Everyday executive function & -.61 & $-.27^{* * *}$ & .14 \\
Everyday executive function $\rightarrow$ School readiness & .01 & $.16^{*}$ & .01 \\
Shyness $\rightarrow$ School readiness & -.02 & -.10 & .01 \\
\hline
\end{tabular}

Note. $N=236$.

${ }^{*} p<.05 .{ }^{* * *} p<.001$.

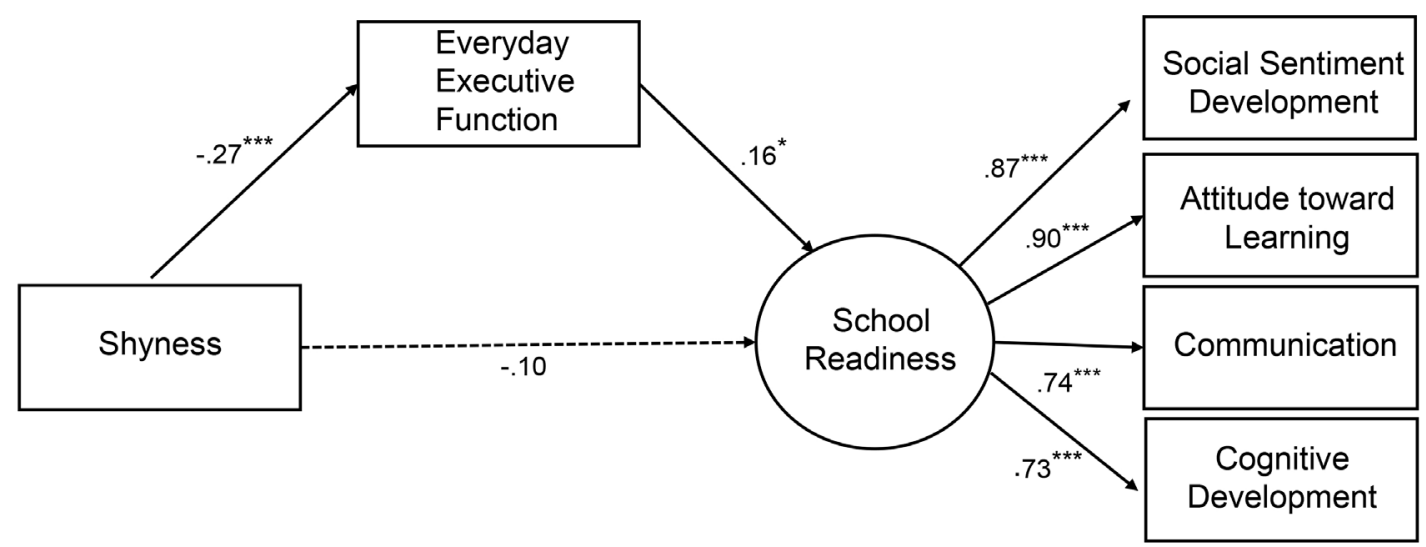

Figure 1. Standardized coefficients for final model.

${ }^{*} p<.05 .{ }^{* * *} p<.001$.

Table 4

Mediating Effects of Preschoolers' Everyday Executive Function on the Shyness and School Readiness

\begin{tabular}{ccccc}
\hline & & \multicolumn{2}{c}{$95 \%$ CI } & \multicolumn{2}{c}{ Lower } \\
\cline { 3 - 6 } Path of variables & $\beta$ & $S E$ & -.02 & -.01 \\
\hline Shyness $\rightarrow$ Everyday executive function $\rightarrow$ School readiness & -.01 & .01 & -.02 & Lper
\end{tabular}

Note. Gender and siblings were included as control variables.

유아의 수줍음은 일상의 실행기능에 부적 영향을 주었다 $(\beta$ $=-.27, p<.001)$. 그리고 일상의 실행기능은 학교준비도에 정 적 영향 주는 것으로 나타났다 $(\beta=.16, p<.05)$. 즉, 유아의 수 줍음이 높을 경우 일상생활에서 나타나는 유아의 실행기능은 낮은 수준을 나타냈고, 이러한 낮은 일상의 실행기능은 사회 정서발달, 학습에 대한 태도, 의사소통, 인지발달 및 일반적 지 식과 같은 학교준비도 수준 감소로 연결되어 수줍음과 학교준 비도 간의 관계를 매개하는 것으로 나타났다. 또한 유아의 수 줍음이 학교준비도에 미치는 직접적인 영향은 유의하지 않은 것으로 나타났다.

마지막으로 일상의 실행기능의 매개효과가 통계적으로 유 의한지 검증하기 위해 편향 수정 부트스트래핑(biased-correct- ed bootstrapping) 분석을 실시하였다(Shrout \& Bolger, 2002). 그 결과는 Table 4에 제시한 바와 같다.

매개효과의 유의성은 신뢰구간의 상위구간(upper bounds) 과 하한값(lower bounds) 사이에 0이 포함되지 않을 때 통계적 으로 유의한 것으로 해석할 수 있다. 본 연구에서 유아의 수줍 음이 일상의 실행기능을 매개하여 학교준비도에 미치는 간접 효과는 유의한 것으로 나타났다 $(\beta=-.01,95 \%$ CI [-.02, -.01]).

즉, 유아의 수줍음은 일상의 실행기능을 매개로 학교준비도 에 영향을 미치는 것으로 검증되었다. 이전 분석에서 유아의 수 줍음이 학교준비도에 미치는 직접적인 영향력이 유의하지 않았 기 때문에 유아의 수줍음이 학교준비도에 미치는 영향에 있어 서 일상의 실행기능이 완전매개를 한다고 유추해 볼 수 있다. 


\section{Discussion}

본 연구를 통해 얻은 결과를 중심으로 요약하고 논의하면 다 음과 같다. 먼저 성별에 따른 학교준비도의 차이를 살펴본 결 과 여아가 남아보다 학교준비도 수준이 높았다. 이는 남아 에 비해 여아의 학교준비도가 높다고 보고한 S. Kwon과 Lee (2018), Y.-J. Park과 Chung (2008)의 연구와 그 맥락을 같이한 다. 또한 Zill과 West (2001)의 연구에서도 여아의 읽기 및 사회 적 능력 수준이 높다고 보고하여 본 연구결과를 지지한다. 이 와 관련하여 Bhang과 Chung (2015)은 만 5세 여아의 특성상 남아에 비해 교사의 칭찬과 격려에 더 민감하여 규칙을 잘 지 키고 과제수행의 완성도가 높다고 하였다. 따라서 통제할 수 없는 변인인 성별이 유아의 학교준비도에 미치는 영향력을 유 아를 둘러싸고 있는 인적 환경 중 어떠한 요인으로 조절할 수 있을지 추가적으로 연구해 볼 필요가 있다.

또한 형제유무에 따른 학교준비도의 차이가 있는 것으로 나타났다. 즉, 형제자매 없이 혼자서 성장한 외동아보다 형제 가 있는 경우 학교준비도 수준이 더 높았다. 이러한 결과는 형 제자매는 가정에서 많은 시간을 함께 보내며 학업행동, 교육 적 열망과 가치를 모델링하고 정보를 공유함으로써 서로의 학 교성과에 영향을 미칠 가능성이 높다고 보고한 선행연구들과 부분적으로 일치하는 결과이다(Nicoletti \& Rabe, 2018). 이와 관련하여 Dunn (1983)은 형제자매 간 상호작용 양상은 또래 관계와 유사한 특성을 가지고 있어 형제와의 관계 경험을 기 반으로 대인관계 형성에 대한 정서적·인지적 발달을 촉진시 킬 수 있다고 하였다. 이처럼 외동아와 형제아는 환경적으로 분명히 다른 상황에 처해 있다. 그러나 형제유무라는 것은 유 아가 선택할 수 없는 타고 난 환경이며 형제유무보다는 외동 아일 지라도 부모로부터 어떻게 양육되어 왔는지가 아동의 발 달에 더 크게 작용할 수도 있다. 따라서 외동아의 비율이 계속 적으로 증가하고 있는 시대적 추세를 감안한다면 형제관계의 의미에 대한 고찰과 함께 외동아에 대한 편견 보다는 외동아 중 수줍음 성향을 갖은 유아의 일상의 실행기능 발달 등을 민 감하게 지원해주려는 노력이 필요하겠다. 또한 본 연구에서는 형제유무에 따른 학교준비도 수준의 차이만을 살펴보았으며, 구체적으로 출생순위에 따른 학교준비도의 차이는 검증하지 않았다. 따라서 추후에는 출생순위에 따른 학교준비도의 차이 에 대해 연구해보고 그 결과를 토대로 출생순위에 따른 학교 준비도 수준 증진을 위해 어떠한 도움을 줄 수 있을지 고찰해 볼 필요가 있겠다.

다음으로 어머니의 취업여부에 따른 학교준비도의 차이는
나타나지 않았다. 이는 2011년 무상보육이 실시되며 어린 시절 부터 기관생활을 시작하는 영유아가 늘어나 또래와 상호작용 할 수 있는 기회가 늘어났다는 점과 교육에 있어 가정보다는 교육기관의 역할이 좀 더 강조되고 있는 점을 통해 해석해 볼 수 있을 것이다. 결과적으로 어머니의 취업여부는 학교준비도 와 통계적으로 유의미한 관련성이 없는 것으로 확인되었다.

주당 사교육 참여 시간은 유아의 학교준비도와 유의한 관 계가 없는 것으로 나타났다. 이는 사교육 참여와 학교준비도 간에 상관관계가 없다고 보고한 Guk (2016)의 연구와 일치 하는 결과이다. 이러한 결과는 유아기 조기 사교육에 많은 시 간을 투자하는 것이 궁극적으로 초등학교 입학을 위한 준비 에 유의미한 영향을 미치지 않는다는 점을 시사한다. Chi 등 (2006)의 연구에서 유아교육기관 교사, 학부모, 초등학교 교사 가 인식하는 학교준비도 요소에 대한 차이를 살펴본 결과 유 아교육기관 교사와 초등학교 교사는 '기능'이나 '성향'을 학교 준비도의 중요한 요소로 인식한 반면, 부모는 '지식'을 더 중요 한 요소로 인식하였다. Sung (2017)의 연구에서는 유아의 학습 사교육의 시작 동기 중 ‘초등 연계'를 꼽은 어머니의 비율이 가 장 높았다. 이러한 연구결과는 초등학교 입학을 앞둔 부모의 불안감과 조바심, 학습 성취에 대한 기대가 배경이 되어 유아 의 조기 사교육 참여로 연결되었으나 궁극적으로 이러한 노력 이 학교준비도 수준 향상에는 영향을 미치지 않았음을 의미한 다. 이는 초연결, 초지능, 자동화로 특징화되는 4 차 산업혁명 시대에 미래형 인재가 가져야 할 핵심역량은 무엇인지, 핵심 역량을 기르기 위해 가정에서는 어떠한 지원해주어야 하는지 인식하고 교육에 대한 부모의 시선이 변화할 수 있도록 부모 지원 프로그램을 강화할 필요가 있음을 시사한다.

이후 측정변인들과 유의한 차이 및 관계가 없었던 어머니 의 취업여부, 주당 사교육 참여 시간을 제외한 성별과 형제유 무를 통제하고 연구모형을 검증하였다. 유아의 수줍음이 학교 준비도에 미치는 영향에서 일상의 실행기능의 매개효과를 검 증한 결과, 먼저 유아의 수줍음은 일상의 실행기능에 부적 영 향을 미치는 것으로 나타났다. 이러한 결과는 수줍음과 실행 기능이 부적 상관관계가 있다고 보고한 선행연구들을 지지하 는 결과이다(Arnold \& Cheek, 1986; Blankson et al., 2011). 수줍 은 유아는 다른 유아 혹은 성인과 함께 낮선 상황에서 학업과 과제를 수행하게 될 경우 평소보다 수줍음과 긴장도가 높아지 게 되고 이는 당면한 과제에 집중하는 능력을 저하시킬 수 있 다. 다시 말해 수줍음은 유아가 일상생활에서 정보를 처리하 고 인지적 유연성을 발휘하여야 하는 상황을 방해할 수 있음 을 의미한다. 
다음으로 유아의 일상의 실행기능이 학교준비도에 정적 영 향을 미쳤다. 즉, 유아가 일상생활에서 자신의 사고와 행동을 관리하고 통제하는 인지적인 조절을 잘 할수록 학교준비도 수 준이 높은 것으로 나타났다. 이러한 결과는 만 5 세의 일상의 실행기능이 높다고 평가된 유아일수록 초등학교 1학년 때 학 업을 방해하는 부적절한 행동이 적은 것으로 나타났다는 선행 연구와 일치하는 결과이다(Nilsen et al., 2017). 일상생활에서 주의를 조절하고 부적절한 행동을 억제하며 자신의 사고와 행 동을 관리하는 능력은 취학 후 학교생활에서 요구되는 다양한 학교준비도 수준을 높이고, 이는 궁극적으로는 학교 적응에도 긍정적인 영향을 미칠 것이다. 반대로 일상의 실행기능 수준 이 낮아 충동을 잘 억제하지 못하고 질서를 지키기 어려우며 문제해결을 위한 계획을 세우거나 이를 수행하는 과정에 어려 움이 있을 경우 또래관계를 맺고 유지하는 것에 어려움을 경 험할 수 있고 더 나아가 학업수행에도 부정적인 영향을 미칠 수 있다고 예측해 볼 수 있다.

마지막으로 유아의 수줍음이 일상의 실행기능을 매개로 학 교준비도에 미치는 영향력이 검증되었다. 이러한 연구결과는 새롭고 불확실한 상황에서 느리거나 억제된 접근을 하는 수줍 음 성향이 강할 경우 유아는 일상생활에서 주의를 조절하고 상황에 맞는 적절한 행동을 하고 대안을 탐색하는 실행기능 이 낮아지고, 실행기능은 다시 유아의 학교준비도 수준을 낮 게 함으로써 궁극적으로 학교 적응이 어려워질 수 있다는 것 을 의미한다. 이는 유아의 수줍음이 어휘능력에 미치는 영향 에서 실행기능이 매개역할을 한다고 본 연구(Blankson et al., 2011)와 유아의 수줍음 특성이 사회적 유능성과 관련이 있지 만 이러한 관련성은 유아의 의도적 통제 수준이 높은 경우 더 이상 유의하지 않았다는 연구(Y. H. Kwon, 2014)가 본 연구 결 과를 부분적으로 지지한다. Blankson 등(2011)의 연구에서 본 수줍음과 어휘 능력과의 관계에서 매개변인으로 본 실행기능 은 낮-밤 과제를 통한 의도적 통제와 숫자를 기억하는 작업기 억 능력을 살펴본 연구이다. 이러한 선행연구 결과를 근거로 의사소통능력과 인지발달 및 일반적 지식을 하위요인으로 포 함하는 학교준비도가 수줍음에 의해 영향을 받을 것이라고 유 추해 볼 수 있었다. 그러나 본 연구에서는 의도적 통제나 작업 기억을 실행기능의 측정변인으로 살펴본 기존의 Y. H. Kwon (2014)이나 Blankson 등(2011)의 연구와는 달리 일상 속에서 의 융통적 사고와 주의 집중력을 포함하는 일상의 실행기능을 측정변인으로 살펴보았다는 점에서 차이와 의미가 있다. 다 시 말해 기억과제나 인지과제에서의 의도적 통제 능력을 실 행기능으로 정의하기 보다는 일상생활 속에서의 융통적 사고
및 주의력을 중심으로 실행기능을 살펴봄으로써 수줍음은 일 상의 실행기능을 매개로 학교준비도에 영향을 미칠 수 있음을 밝혔다는 것에 의의가 있다. 또한 Blankson 등(2011)의 어휘 능 력과 Y. H. Kwon (2014)의 사회적 유능성의 개념을 모두 포괄 하면서도 학습에 대한 태도, 의사소통, 인지 및 일반적 지식 등 보다 폭넓은 발달의 전반적 측면을 살펴볼 수 있는 학교준비 도를 종속변인으로 보았기에 본 연구결과는 선행연구와 다른 의의를 가질 수 있다고 사료된다.

본 연구결과를 근거로 유아의 타고난 기질적 성향인 수줍 음을 극복하기 위한 프로그램 개발의 활성화와 효과 검증 연 구들을 통해 낮선 상황이나 새로운 사람 앞에서 긴장하고 위 축되는 수줍은 유아의 특성을 완화 시켜주려는 노력과 개입이 더욱 필요함을 제안한다. 또한 무엇보다 중요한 것은 수줍음 이 많다고 인식되는 유아에 대한 성인의 접근 방식일 것이다. 실제로 수줍은 유아들을 관찰해보면 타인의 작은 행동에도 금 세 긴장하는 반응을 나타낸다. 따라서 수줍은 유아와 소통하 는 방식에 있어 유아의 의도를 살피며 사려 깊은 태도로 접근 할 때, 수줍은 유아 또한 낮선 성인과의 관계에서 느낄 수 있는 심리적 거리감을 점차 좁혀 일상적으로 행동할 수 있을 것이 다. 이러한 노력을 통해 수줍은 유아가 일상생활에서 주의를 조절하고 부적절한 행동은 억제하며 자신의 사고와 행동을 관 리하는 능력이 잘 발휘될 수 있도록 하였을 때, 학교에서 요구 되는 과업이나 교육과정을 보다 원활하게 수행할 수 있는 사 회·정서적인 능력, 호기심, 열정, 끈기와 같은 학습에 대한 태 도, 의사소통 기술이 증진되어 초등학교 교육에 성공적으로 참여하고 적응할 수 있게 됨을 알 수 있다.

한편 유아의 수줍음이 학교준비도에 미치는 직접적인 영향 력은 유의하지 않았다. 이는 유아의 수줍음이 학업성취도에 직접적인 영향력을 발휘하지 못했다고 밝힌 선행연구와 유사 한 맥락으로 이해할 수 있다(Walker \& Henderson, 2012; Zhang et al., 2017). 또한 서구 문화권에서는 수줍음과 관련된 많은 속 성들을 통해 기질적으로 수줍음이 있거나 조용한 유아를 부정 적으로 평가하는 경향을 보여 왔다. 그러나 동아시아 문화권 에서는 전통적으로 집단과의 조화를 중요시하여 겸손하고 조 용한 성격이 보다 적응적인 것으로 여겨져 왔으며, 실제 한국 을 포함한 아시아 국가의 유아들은 서구의 아동들에 비해 더 욱 억제적인 행동 패턴을 보이는 것으로 나타나(Rubin et al., 2006), 본 연구결과 또한 이와 같은 배경을 통해 해석해 볼 수 있을 것이다. 다시 말해 본 연구에서 유아의 학교준비도를 평 정한 교사의 관점에서 본다면 단순히 수줍거나 소극적인 유아 에 대해 학교준비도 점수를 낮게 평정하지 않았을 것이라고 
예측해 볼 수 있다.

본 연구에 대한 제한점을 밝히면서 후속연구에 대한 제언 을 하면 다음과 같다.

첫째, 본 연구는 서울·경기·강원·대전·충남 지역 유아교 육기관에 재원하고 있는 유아를 대상으로 하여 표본의 다양성 을 획득하려 노력하였다. 그러나 다양한 유형의 어린이집과 유치원을 균등하게 표집하지 못하였기에 연구결과를 일반화 하기에는 어려움이 있다. 또한 연구대상 중 $43 \%$ 정도가 직장 어린이집에 재원중인 유아였다. 직장 어린이집의 경우 다른 유형의 기관과 비교하였을 때 물리적인 환경이나 인적 자원 등에 있어 차이를 보일 수 있고 이러한 요인이 학교준비도에 영향을 미쳤을 수도 있다. 따라서 후속연구에서는 유아교육기 관의 유형별 비율을 고려하여 표본의 대표성을 확보한 후 비 교연구를 해보거나 질적 수준을 함께 조사한 후 통제하여 보 다 정확한 분석을 실시해 볼 필요가 있겠다.

둘째, 본 연구에서 사용된 학교준비도 척도는 미국의 National Education Goals Panel의 목표에 따라 모든 유아들이 학습할 준비가 된 상태로 학교에 입학하는지에 대한 정보 수 집을 위해 사용된 도구이다. 다시 말해 취학 전 유아가 학교 생활에 적응할 수 있는 기본적인 능력이나 자질을 어느 정도 갖추었는지 선별하고 개입하는 것을 목적으로 한다. 그러나 KICCE (2018)의 유아교육 보육 주요 통계자료에 따르면 만 $3-5$ 세의 경우 약 $90.7 \%$ 가 유아교육기관을 이용하고 있다. 즉, 무상보육 시행으로 이른 영유아기부터 보육기관을 이용하는 아동수가 늘어났고, 대부분의 유아가 누리과정을 통해 집단생 활에 참여하며 유아기 발달과정을 거치고 있다. 이러한 점을 고려해 볼 때 학교준비도 문항 내용이 한국의 취학 전 유아에 게 적용되기에는 난이도가 낮을 수 있음이 유추되며, 그렇기 에 어떤 지역이나 계층에서든 비교적 높은 점수를 획득할 수 있어 개인 간 편차가 낮은 원인으로 작용될 수 있었다고 사료 된다. 따라서 학교준비도 척도 내용 검토를 통해 현재 한국 유 아들의 학교준비도 수준을 변별력 있게 선별해 낼 수 있는 문 항들로 재구성되어야 할 것이다.

셋째, 본 연구에서는 학교준비도에 영향을 미칠 수 있는 유 아의 사교육 참여여부와 주당 사교육 참여 시간에 대해 조사 하였다. 그러나 주당 사교육 참여 시간이 학교준비도에 미치 는 영향력을 구체적으로 파악하기 위해서는 사교육과 관련된 다양한 요인들이 고려되어야 하는데, 본 조사에서는 참여 여 부(학습지, 가정방문 수업, 학원, 문화센터 등) 및 주당 사교육 참여 시간에 대한 조사에만 그쳐 구체적으로 유아의 사교육 참여가 어떠한 형태(개인 혹은 그룹)로 이루어지는지, 주로 어
떤 과목에 참여하고 있는지, 참여하는 가지 수는 어떠한지에 대한 조사가 미흡하였다는 제한점을 갖는다. 따라서 후속연구 에서는 유아의 사교육 참여와 관련된 다양한 요소를 고려해 볼 필요가 있겠다.

넷째, 본 연구에서는 연구대상의 내적 요인에 초점을 두어 기질적 특성인 수줍음과 인지적 특성인 일상의 실행기능이 학 교준비도에 미치는 영향에 대해 살피고자 하였다. 그러나 추 후 연구에서는 내적 요인과 함께 유아를 둘러싸고 있는 대인 적 요인(부모, 교사, 유아교육기관 환경 등)을 함께 살펴봄으 로써 성별이나 형제유무, 기질과 같은 통제할 수 없는 요인을 인적 환경 중 어떠한 요인으로 조절할 수 있을지 추가적으로 연구해 볼 필요가 있다.

다섯째, 일상의 실행기능을 질문지로 평정하는 것은 부자 연스러운 실험상황에서 나타날 수 있는 긴장이나 사회적 기대 에 맞는 행동이 아닌, 자연스러운 상황에서의 실제 능력을 평 가할 수 있다는 장점은 있으나 평정자인 부모의 회상에 근거 한 평가로 왜곡된 기억이나 정확하지 않을 수 있는 정도에 대 한 평가가 있을 수도 있다는 한계점을 가진다. 따라서 추후 연 구에서는 일상의 실행기능을 보다 객관적으로 평가할 수 있는 방법에 대한 심도 있는 고민이 필요하겠다.

위와 같은 제한점을 가지고 있음에도 불구하고 지금까지 살펴본 바에 근거하여 본 연구가 가지는 시사점과 의의, 학교 준비도 수준 향상을 위한 구체적인 방안을 요약하면 다음과 같다.

첫째, 본 연구는 유아의 학교준비도를 이해함에 있어 성별 과 형제유무에 따른 학교준비도의 차이가 있음을 밝혔으며, 어머니의 취업여부에 따른 학교준비도의 유의미한 차이가 없 고, 주당 사교육 참여 시간과 학교준비도 간의 관계가 적은 것 으로 나타났다. 이를 통해 가정과 유아교육기관에서 유아의 성별과 형제유무에 따라 학교준비도 향상을 위한 지도 방법이 달라져야 함에 대한 근거를 제시하였다. 또한, 부모 면담이나 초등 준비를 위한 간담회 개최 시 어머니의 취업여부나 사교 육의 영향보다는 성별과 형제유무를 고려한 내용으로 구성되 도록 기초자료를 제공한 것에 의의가 있다. 따라서 남아, 외동 아의 낮은 학습준비도 수준에 주목하기 보다는 이들이 가지고 있는 내적 자원을 활용하여 학교준비도 수준 향상을 도모할 수 있는 교육이 이루어져야 할 것이다.

둘째, 본 연구는 국내에서는 비교적 연구가 덜 이루어진 기 질적 측면의 수줍음과 취학 전 유아의 학교준비도 간의 관계 에 대해 고찰해 보았으며, 수줍음과 학교준비도의 관계를 매 개하는 인지적 능력이 있음을 밝혔다는 것에 의의가 있다. 이 
러한 결과는 유아의 학교준비도 수준 향상에 있어 인지적 능 력인 일상의 실행기능에 대한 중요성을 재고시켰고, 학교준비 도 향상을 위한 교육적 개입과 전략을 수립하는 것에 있어 중 요한 시사점을 제공한다. 즉, 본 연구결과는 수줍은 유아의 학 교준비도 수준 향상은 수줍음에 대한 중재적 접근을 통해서도 가능하지만, 일상생활에서의 실행기능을 고양시킴으로써도 가능함을 제시하고 있다. 이와 같이 유아 일상의 실행기능을 향상 시킬 수 있는 개입과 전략이 필요함에도 불구하고, 국내 에서는 일반 유아를 대상으로 한 실행기능 향상 프로그램 적 용 연구는 매우 부족한 반면, 주의력결핍과잉행동장애아와 학 습부진아 등을 대상으로 한 연구만이 진행되어 왔다. 따라서 일반 유아의 일상의 실행기능 향상을 위한 프로그램을 개발하 고 적용하려는 노력이 필요할 것이다.

이처럼 추후 연구에서 유아의 학교준비도에 영향을 미치는 요인을 보다 다양한 차원에서 함께 고려한다면 유아의 학교준 비도 수준 향상에 대한 통합적인 이해를 도모할 수 있을 것이다.

\section{Notes}

This article is a part of the first author's Master's thesis submitted in 2020 .

\section{Conflict of Interest}

No potential conflict of interest relevant to this article was reported.

\section{References}

\section{In English}

Arnold, A. P., \& Cheek, J. M. (1986). Shyness, self-preoccupation and the stroop color and world test. Personality and Individual Differences, 7(4), 571-573. doi:10.1016/0191-8869(86)90135-2

Best, J. R., Miller, P. H., \& Naglieri, J. A. (2011). Relations between executive function and academic achievement from ages 5 to 17 in a large, representative national sample. Learning and Individual Differences, 21(4), 327-336. doi:10.1016/j.lindif.2011.01.007

Blankson, A. N., O’Brien, M., Leerkes, E. M., Marcovitch, S., \& Calkins, S. D. (2011). Shyness and vocabulary: The roles of executive functioning and home environmental stimulation. Merrill-Palmer Quarterly, 57(2), 105-128. doi:10.1353/mpq.2011.0007

Coplan, R. J., Prakash, K., O’Neil, K., \& Armer, M. (2004). Do you 'want' to play? Distinguishing between conflicted shyness and social disinterest in early childhood. Developmental Psychology, 40(2), 244-258. doi:10.1037/0012-1649.40. 2.244

Dunn, J. (1983). Sibling relationships in early childhood. Child Development, 54(4), 787-811. doi:10.2307/1129886

Gioia, G. A., Isquith, P. K., Guy, S. C., \& Kenworthy, L. (2000). Test review behavior rating inventory of executive function. Child Neuropsychology, 6(3), 235-238. doi:10.1076/ chin.6.3.235.3152

Jordan, N. C., Kaplan, D., Nabors Oláh, L., \& Locuniak, M. N. (2006). Number sense growth in kindergarten: A longitudinal investigation of children at risk for mathematics difficulties. Child Development, 77(1), 153-175. doi:10.1111/ j.1467-8624.2006.00862.x

Ludwig, R. P., \& Lazarus, P. J. (1983). Relationship between shyness in children and constricted cognitive control as measured by the Stroop Color-Word Test. Journal of Consulting and Clinical Psychology, 51(3), 386-389. doi:10.1037/0022006x.51.3.386

Murphey, D. A., \& Burns, C. E. (2002). Development of a comprehensive community assessment of school readiness. Early Childhood Research \& Practice, 4(2), 1-14.

National Education Goals Panel. (1992). The national education goals report 1992: Building a nation of learners. Washington, DC: Government Printing Office.

Nicoletti, C., \& Rabe, B. (2018). Sibling spillover effects in school achievement. Journal of Applied Econometrics, 34(4), 482501. doi:10.1002/jae.2674 doi:10.1002/jae.2674

Nilsen, E. S., Huyder, V., McAuley, T., \& Liebermann, D. (2017). Ratings of Everyday Executive Functioning (REEF): A parent-report measure of preschoolers' executive functioning skills. Psychological Assessment, 29(1), 50-64. doi:10.1037/ pas0000308

Rubin, K. H., Hemphill, S. A., Chen, X., Hastings, P., Sanson, A., Coco, A. L.,...Cui, L. (2006). A cross-cultural study of behavioral inhibition in toddlers: East-West-North-South. International Journal of Behavioral Development, 30(3), 219226. doi: $10.1177 / 0165025406066723$

Schaefer, B. A., \& McDermott, P. A. (1999). Learning behavior and intelligence as explanations for children's scholastic achievement. Journal of School Psychology, 37(3), 299-313. doi:10.1016/s0022-4405(99)00007-2

Shrout, P. E., \& Bolger, N. (2002). Mediation in experimental and nonexperimental studies: New procedures and recommendations. Psychological Methods, 7(4), 422-445. 
doi:10.1037/1082-989X.7.4.422

Valiente, C., Lemery-Chalfant, K., \& Castro, K. S. (2007). Children's effortful control and academic competence: Mediation through school liking. Merrill-Palmer Quarterly, 53(1), 1-25. doi:10.1353/mpq.2007.0006

Walker, O. L., \& Henderson, H. A. (2012). Temperament and social problem solving competence in preschool: Influences on academic skills in early elementary school. Social Development, 21(4), 761-779. doi:10.1111/j.1467-9507.2011.00653.x

Zelazo, P. D., \& Carlson, S. M. (2012). Hot and cool executive function in childhood and adolescence: Development and plasticity. Child Development Perspectives, 6(4), 354-360. doi:10.1111/j.1750-8606.2012.00246.x

Zhang, L., Eggum-Wilkens, N. D., Eisenberg, N., \& Spinrad, T. L. (2017). Children's shyness, peer acceptance, and academic achievement in the early school years. MerrillPalmer Quarterly, 63(4), 458-484. doi:10.13110/ merrpalmquar1982.63.4.0458

Zill, N., \& West, J. (2001). Entering kindergarten: A portrait of american children when they begin school. Finding from the condition of education, 2000. Retrieved from ERIC database. (ED448899)

Zimbardo, P. G., Pilkonis, P. A., \& Marnell, M. E. (1977). Shyness: What it is, what to do about it. New York: Addoson-Wesley.

\section{In Korean}

Bhang, E.-J., \& Chung, O.-B. (2015). The influence of kindergarten teachers' teaching behaviors on young children's school readiness. Early Childhood Education \& Care, 10(3), 25-51. doi:10.16978/ecec.2015.10.3.002

Cha, M., \& Kim, K. (2018). The Effects of temperament and maternal parenting on preschoolers' executive function. Journal of Parent Education, 10(1), 115-138.

Chi, S. A., Jung, D. H., Jeung, H. E., Ahn, J. S., \& Park, E. Y. (2006). A comparison of early childhood teachers', parents', and elementary teachers' awareness of elementary school readiness. The Journal of Korea Open Association for Early Childhood Education, 11(5), 227-249.

Cho, S.-Y. (2002). The relationship of HOME and personality with preschool children's school readiness. Journal of Korean Home Management Association 20(4), 103-111.

Choi, J.-H., \& Park, H. W. (2010). The influence of home environment and children's characteristics upon school readiness. Korean Journal of Child Studies, 31(1), 113-124.

Chung, J. (2019). Factors affecting school adaptation of first-grade elementary school children of working mothers. Korean Journal of Human Ecology, 28(3), 185-199. doi:10.5934/ kjhe.2019.28.3.185

Guk, D.-S. (2016). The relationship between preschoolers' private education experience and parents' perception of school readiness
(Master's thesis). Retrieved from http://www.riss.kr/link?id= T14010305

Jeong, J. H., \& Kang, M. J. (2019). The effect of maternal rejective parenting attitude on children's leadership: Mediating effect of self-esteem and gender difference. Family and Environment Research, 57(3), 315-328. doi:10.6115/fer.2019.023

Jun, E.-O., \& Choi, N. (2015). The relationships between home environment stimulation and kindergarteners' school readiness: The mediating effect of preschool adjustment. Korea Journal of Child Care and Education 94, 93-119.

Jung, S. Y. (2014). The effects of maternal employment status and the type of the work on the academic achievement levels of adolescents. Korean Journal of Youth Studies, 21(10), 1-22.

Kim, J.-H., Kim, K.-R., \& Yu, E.-Y. (2011). Investigation of parents' beliefs about young children's school readiness before entering elementary school by participating in early education. Early Childhood Education Research \& Review, 15(1), 99-116.

Kim, J. W., \& Shon, G. H. (2009). A study on the causal relationship between birth order, existence and non-existence of siblings and motor development. Journal of Early Childhood Education \& Educare Administration, 13(1), 231-253.

Kim, Y., \& Kwak, K. (2014). The relation between executive function of four-year-olds and reading ability of six-yearolds: A short-term longitudinal exploration. The Korean Journal of Developmental Psychology, 27(2), 23-37.

Kim, Y., Koo, J. Y., \& Kim, H. K. (2019). Longitudinal effects of mothers' parenting stress on children's academic achievement during the transition to school: The double mediation effects of home environment and school readiness. Korean Journal of Early Childhood Education, 39(3), 191-213. doi:10.18023/ kjece.2019.39.3.008

Korea Institute of Child Care and Education. (2018). $2017 \mathrm{Yu}$ agyo-yug bo-yug ju-yo tonggye [2017 유아교육 보육 주요통 계] (Report No. 2018-01). Seoul: Author.

Kwon, S., \& Lee, K. (2018). Effects of parent-child interaction and caregiving supports on the school readiness of preschoolers: Focusing on working mothers' job characteristics. Korean Journal of Child Care and Education Policy, 12(2), 57-81. doi:10.5718/kcep.2018.12.2.57

Kwon, Y. H. (2014). Children's social competence: Effects of negative emotionality, shyness and effortful control. Korean Journal of Child Education and Care, 14(4), 215-235.

Lee, J. W., Park, J.-A., \& Park, K. (2015). Estimated research on infant and childcare costs (III) (Report No. 2015-28). Seoul: Korea Institute of Child Care and Education.

Lee, J., Kim, K., Song, S., Lee, Y., Kim, J., Kim, S., \& Kim, S. (2015). Panel Study on Korean Children 2015 (PSKC) (Report No. 2015-33). Seoul: Korea Institute of Child Care and Education. 
Lee, K.-O. (2004). Validation study for CBQ scale with Korean children. Journal of Early Childhood Education, 24(5), 101120.

Lee, S. H., \& Hwang, H. J. (2014). A study of the variables affecting school readiness of preschool children. Journal of Childrens Literature and Education, 15(2), 385-410.

Lee, W. (2017). The influence of teacher interaction on the child school readiness: Mediation effect comparison of children's teacher and institute preference in two groups. Korean Journal of Child Studies, 38(6), 93-103. doi:10.5723/ kjcs.2017.38.6.93

Min, M. (2019). The effects of teacher-child Interaction, peer play interaction, and social competence preschoolers on the school readiness: Multigroup analysis across gender. Journal of Future Early Childhood Education, 26(3), 1-22. doi:10.22155/jfece.26.3.1.22

Oh, Y. J., \& Moon, H. J. (2013). Effects of maternal employment, child's internet immersion, resilience and parent-child relationships on their school life adjustment. Korean Journal of Human Ecology, 22(6), 559-569. doi:10.5934/kjhe.2013. 22.6.559

Park, N. J., \& Cho, I. S. (2001). A study on the verbal development of infants- Focusing on expression language, sentence, and vocabulary-Focusing on expression language, sentence comprehension, and vocabulary-. Korea Journal of Child Care and Education, 27, 189-207.

Park, Y.-J., \& Chung, O.-B. (2008). The school readiness inventory for kindergarteners: Development and validation. The Korean Journal of Human Development, 15(1), 23-47.

Park, Y.-J., \& Chung, O.-B. (2010). A study on the school readiness of preschoolers in Korea. The Korean Journal of Human Development, 17(3), 37-54.

Park, Y.-N., \& Doh, H.-S. (2006). The effectiveness of a program for overcoming shyness in kindergarteners. Korean Journal of Child Studies, 27(5), 109-122.

Park, Y. Y., \& Jeon, G.-Y. (2009). Sibling relationships. Korean
Journal of Child Studies, 30(6), 43-59.

Song, M. (2019). The mediating effect of child-peer play interaction on the relationship between teacher-child interaction and children's readiness for school. Korean Journal of Early Childhood Education, 39(1), 103-123. doi:10.18023/kjece. 2019.39.1.005

Shim, M. K., \& Woo, J. Y. (2019). The mediating effects of parenting stress, child's temperament and emotional regulation in the relationship between mother's parenting sensitivity and child's school readiness. Korean Journal of Child Studies, 40(5), 6982. doi:10.5723/kjcs.2019.40.5.69

Sung, M. (2017). Study on the correlation between children's private education, mother's parental intelligence and maternal parenting beliefs (Master's thesis). Retrieved from http:// www.riss.kr/link?id=T14576739

Yi, M., \& Kwon, M. (2008). Differences of story construction ability between temperamentally shy and non-shy kindergartners. The Journal of Educational Studies, 39(1), 157-180.

Yoon, J., Lee, M., \& Lee, Y. (2017). The effect of mother's parenting stress and expectation of child's school adaptation on school readiness as for their child's gender. Korean Journal of Children's Media, 16(1), 131-155. doi:10.21183/ $\mathrm{kjcm} .2017 .03 .16 .1 .131$

\section{ORCID}

Yu Ri Ryu http://orcid.org/0000-0002-3704-8433

Min Ju Kang http://orcid.org/0000-0002-1881-8076

Received February 29, 2020

Revision received March 23, 2020

Accepted April 8, 2020 